\title{
HOURLY CALCULATION METHOD OF BUILDING ENERGY DEMAND FOR SPACE HEATING AND COOLING BASED ON STEADY-STATE HEAT BALANCE EQUATIONS
}

\author{
Edmundas Monstvilas ${ }^{1}$, Vytautas Stankevičius ${ }^{2}$, Jūratė Karbauskaité ${ }^{3}$, \\ Arūnas Burlingis ${ }^{4}$, Karolis Banionis ${ }^{5}$ \\ Institute of Architecture and Construction of Kaunas University of Technology, \\ Tunelio g. 60, LT-44405 Kaunas, Lithuania \\ E-mails: ${ }^{1}$ asi_monstvilas@yahoo.com; ${ }^{2}$ v.stankevicius@ktu.lt; ${ }^{3}$ jukarb@asi.lt (corresponding author); \\ ${ }^{4}$ arunas.burlingis@asi.lt; ${ }^{5}$ karolis.banionis@ktu.lt
}

Received 14 Sept. 2011; accepted 16 Jan. 2012

\begin{abstract}
Correct evaluation of solar heat gains through fenestration into the rooms has a great impact on energy demand calculations for buildings. This article presents an hourly energy demand calculation method for heating and cooling, which considers the fact that the solar radiation flow passed through the transparent fenestration into the rooms is not adequate to the thermal energy flow. This method considers that the thermal energy flow in the rooms transformed from solar thermal radiation depends on the short-wave thermal radiation absorption coefficient of internal surfaces of the rooms. The value of short-wave thermal radiation absorption coefficient forms a considerable impact on the flow of thermal energy gains in the room. The presented method differs from others on that score that it considers additionally physical lows, according to which the solar short-wave thermal radiation energy admitted into the room is converted into the thermal energy. This hourly method enables precise calculating the hourly mean of indoor temperature and energy demand for heating and cooling of the buildings during the day.
\end{abstract}

Keywords: energy, heat gains, solar radiation, hourly calculation method.

\section{Introduction}

The fundamental requirements of the new EPBD directive are aimed at the further decrease of energy consumption in buildings (Directive 2010/31/EU). Great attention is paid to the ability to construct only low and very low-energy using buildings in the future. Solar heat gains admitted inside the buildings make a considerable impact on the indices of the building energy consumption. These gains take place during the whole heating season. At the beginning and end of the heating season, solar thermal radiation is intensive enough and heat gains could cover a large extent of heat losses in buildings. Therefore, the development of calculation precision of solar heat gains and real evaluation has a big influence on the indices of building energy demand (Yohanis, Norton 1999).

The calculation of solar heat gains into buildings has been improved and is more detailed in the new standard LST EN ISO 13790 (2008) in comparison with its edition of 2004. Heat gains are calculated according to the annual, monthly and hourly calculation methods. When yearly and monthly mean value calculation methods are applied, the average daily data on global solar radiation are used (LST EN ISO 13790 2008; Van Dijk et al. 2005). In other words, these calculation methods assume that solar thermal heat flow density is the same at every hour of the day. The hourly calculation method is more detailed be- cause it uses the data of hourly solar radiation during 24 hours. However, even this method is not perfect enough. Some additional conditions must be fulfilled in order to prevent divergences of calculation results (LST EN ISO 13790 2008), but in the present edition of the mentioned standard, they are not described.

We have studied the calculation methods of solar gains in a building and composed a new hourly calculation method which enables calculating hourly solar heat gains and temperature in the rooms during the day more precisely as the laws of solar radiation transformation into long wave thermal energy are taken into account.

\section{Theoretical premises}

For use within the context of building regulations, and in particular for checking compliance with a EP requirement (maximum energy performance level), there is an urgent need for simplified methods that fulfil a number of basic requirements (Van Dijk et al. 2005; Ginevičius et al. 2008).

Normally it is considered that heat gains in buildings can occur due to the internal heat emissions, long wave sky radiation and solar thermal radiation. These heat gains are different by their nature and physical properties. Therefore, by setting heat balance equations the peculiarities and nature of each kind of heat gains have to be taken into account. 


\subsection{The assessment of internal heat gains}

In most cases, internal heat gains inside the building occur due to the thermal energy flow from warmer internal surfaces than indoor air temperature, i.e. due to the emitted heat from humans and various appliances (domestic electrical appliances, lighting, etc.). Thermal energy from these warmer internal surfaces is usually delivered by two ways: by convection and by radiation. Radiant thermal transmission can be calculated according to the equations of long wave thermal radiation energy transfer between the surfaces with different temperatures.

Internal heat gains could be precisely calculated if accurate areas and temperatures of emitting surfaces were known, but this is not the case. Therefore, for the calculation of energy consumption in buildings the normative values of internal heat gains are used, which most frequently are given as energy flow to floor area unit $q_{\text {int }}, \mathrm{W} / \mathrm{m}^{2}$ (LST EN ISO 13790 2008). Heat transfer mechanism of internal heat gains is the same as in heating devices (radiators and similar equipment), i.e. it is based on the laws of thermal convection and long wave thermal radiation. Thus, it can be stated that during the heating season internal heat gains are decreasing thermal energy flow required for heating the building in value of $\Phi_{i n}$. Then the decrease of thermal energy flow for heating $\Phi_{i n, t}, \mathrm{~W}$, at every time step $t$ can be calculated as follows:

$$
\Phi_{\text {in }, t}=q_{\text {int }, t} \cdot A_{f},
$$

where: $q_{i n, t}-$ internal heat gains at the time step $t$ for floor area unit of the heated spaces (rooms), W/m² $A_{f}$ - floor area of the heated spaces (rooms), $\mathrm{m}^{2}$.

\subsection{The assessment of long wave sky radiation}

Different temperatures between the sky dome and enclosures of the building cause heat exchange between these surfaces. The heat exchange on the external surfaces of the building enclosures occur as thermal convection and long wave thermal radiation (ASHRAE 2009; Banionis et al. 2011; LST EN ISO 6946 2008). The surface heat transfer coefficient at external surfaces of the building envelope $h_{s e}$ is determined from the sum of convective $h_{s e, c}$ and radiative $h_{s e, r}$ surface heat transfer coefficients (ASHRAE 2009; Banionis et al. 2011; LST EN ISO 6946 2008):

$$
h_{s e}=h_{s e, c}+h_{s e, r} \text {. }
$$

The hemispherical emissivity value for most of the building product surfaces, including glass panes, makes up about 0.9 (ASHRAE 2009), which means that the surfaces absorb almost all energy of the emitted long wave radiation. Therefore, only a very small part of this radiation strikes the inside of the building directly even through glazed surfaces. Long wave radiation from the sky dome is affecting the external surfaces of the building envelope decreasing the temperature of those surfaces. During the heating season, due to the reduced temperatures of external surfaces of the envelope, extra transmission heat losses occur and the required heating energy flow is enlarged by the value of $\Phi_{r}$. This value $\left(\Phi_{r}, \mathrm{~W}\right)$ could be calculated on the basis of calculation principles from LST EN ISO 13790 (2008) and after itemizing the equations (LST EN ISO 13790 2008):

$$
\Phi_{r}=\frac{h_{s e, r} \cdot \Delta \theta_{e r}}{h_{s e, c}+h_{s e, r}} \cdot \sum_{k=1}^{n}\left[\varepsilon_{l w, s e, k} \cdot F_{r, k} \cdot U_{k} \cdot A_{k}\right],
$$

where: $k$ - number of appropriate building elements; $F_{r, k}$ - form factor between the external surface of the building element and the sky (for unshaded vertical elements $F_{r, k}=0.5$, for unshaded horizontal elements $\left.F_{r, k}=1\right)$ (LST EN ISO 137902008$) ; h_{s e, r}$ - external surface radiative heat transfer coefficient could be taken as equal to $5 \cdot \varepsilon_{\mathrm{lw}}, \mathrm{W} /\left(\mathrm{m}^{2} \cdot \mathrm{K}\right)$; it corresponds to the average temperature of $10{ }^{\circ} \mathrm{C} ; \Delta \theta_{e r}$ - average difference between the external air temperature and apparent sky temperature; in the sub-polar areas $\Delta \theta_{e r}=9 \mathrm{~K}$, in the tropics $\Delta \theta_{e r}=$ $13 \mathrm{~K}$, in the intermediate zones $\Delta \theta_{e r}=11 \mathrm{~K}$ (LST EN ISO $137902008) ; \varepsilon_{l w, s e, k}-$ hemispherical emissivity of external surface of the element $k ; U_{k}$ - thermal transmittance of the element $k, \mathrm{~W} /\left(\mathrm{m}^{2} \cdot \mathrm{K}\right) ; A_{k}$ - overall projected area of the element $k$ with the given orientation and tilt angle $\mathrm{m}^{2}$.

Eq. (3) is used for opaque and transparent building elements.

\subsection{The assessment of solar radiation}

\subsubsection{Heat exchange at external surfaces of enclosures}

The values of absorption coefficient for solar radiation $\alpha_{s w}$ of the surfaces of the building products in most cases are lesser than the values of long wave hemispherical emissivity $\varepsilon_{l w}$ (ASHRAE 2009; Banionis et al. 2011; Urbikain, Sala 2009). A part of short wave solar radiation is absorbed by both external opaque and transparent surfaces. Therefore, a part of short wave solar radiation does not pass inside the building even through glazed enclosures. Heat exchange at external surfaces of enclosures proceeds as thermal convection and long wave thermal radiation (ASHRAE 2009; Banionis et al. 2011; LST EN ISO 6946 2008). Surface thermal transmittance of external surfaces of enclosures $h_{s e}$ is calculated according to Eq. (2). Due to the impact of solar radiation, the temperature of external surfaces of both opaque and transparent enclosures becomes higher than the outdoor air temperature. The temperature of the inside surfaces of enclosures is increasing as well. This causes additional heat transfer at internal surfaces of enclosures which have a mechanism similar to the heat transfer mode in heating devices (radiators and similar equipment), i.e. it is based on the laws of thermal convection and long wave thermal radiation. As the external surfaces of the building are impacted by short wave solar radiation during the heating season in this way decreasing the transmission heat losses, the required thermal energy flow for heating is reduced by the value $\Phi_{s o l, a b}$. on the basis of the calculation principles in LST EN ISO 13790 (2008). After itemizing the equations given there, this value $\Phi_{s o l, a b, t}, \mathrm{~W}$, at every time step $t$ could be calculated as follows:

$$
\Phi_{s o l, a b, t}=\frac{I_{s o l, k, t}}{h_{s e, c}+h_{s e, r}} \cdot \sum_{k=1}^{n}\left(\alpha_{s w, s e, k} \cdot F_{s h, k} \cdot U_{k} \cdot A_{k}\right),
$$


where: $A_{k}$ - area of the element $k$ of a given orientation and tilt angle, $\mathrm{m}^{2} ; I_{\text {sol, }}$ - the mean global solar radiation over the time step of the calculation onto appropriate element $k$ of a given orientation and tilt angle, $\mathrm{W} / \mathrm{m}^{2}$; $F_{s h, k}$ - shading factor by external obstacles for the surface $A_{k} ; \alpha_{s w, s e, k}$ - solar radiation absorption coefficient of the element $k$ of external surfaces of the building.

\subsubsection{The assessment of solar thermal energy transfer into the rooms through transparent elements}

Transparent elements of buildings (e.g. glazed areas of windows) are partly transparent to short wave solar radiation. The transparency for this radiation is characterized by total solar energy transmittance $g_{g l, k}$ of the transparent element $k$ (LST EN ISO 13790 2008; Carmody et al. 2004):

$$
g_{g l, k}=0.9 \cdot g_{g l, n, k},
$$

where: $g_{g l, n, k}$ - solar energy transmittance for solar radiation which is normal to the transparent element $k ; 0.9-$ correction factor due to the tilt angle between the solar beam and transparent element.

The methods currently used for the calculations (LST EN ISO 13790 2008; Nielsen, Svendsen 2005) and research results of external solar gains (Yohanis, Norton 1999; Kalema et al. 2008; Zinzi et al. 2008; Carmody et al. 2004; Corrado et al. 2007; Orosa, Oliveira 2010; Sjösten et al. 2003) do not consider the fact that since solar radiation penetrates the transparent elements of the building, the wave lengths of thermal radiation do not change, i.e. the solar radiation remains short-wave. The same basis is used for the simulation of thermal behaviour at window surfaces (Jurelionis, Isevičius 2008). The admitted solar energy inside the building does not directly heat the indoor air. The heat exchange between the admitted solar energy and indoor air could only occur in the form of radiation, but air is highly transparent to the thermal radiation and therefore, this exchange does not occur. The short wave solar energy admitted into the building could be absorbed only by the internal surfaces of the rooms. The value of absorption coefficient for solar radiation $\alpha_{s w}$ for most of the indoor finishing products comprises about 0.6 ; thus, the inside surfaces of the rooms (partitions, floor and ceiling slabs, etc.) absorb only a part of total solar energy admitted inside the building. As the temperature of the inside surfaces rises up due to the solar energy admitted indoor, the convective heat exchange between the mentioned inside surfaces and indoor air begins, and for this reason, the indoor air is heated up. During this convective heat exchange, the inside surfaces lose a part of absorbed thermal energy. Thus, according to the calculation methods and equations given in LST EN ISO 13790 (2008), only short wave solar energy flow $\Phi_{s o l, s w, t}, \mathrm{~W}$ admitted inside the building at every time step $t$ can be calculated:

$$
\begin{aligned}
\Phi_{s o l, s w, t}=\sum_{k=1}^{n}\left[F_{s h, k} \cdot F_{s h, g l, k} \cdot g_{g l, k} .\right. \\
\left.\left(1-F_{F, k}\right) \cdot A_{w d, k} \cdot I_{s o l, k, t}\right],
\end{aligned}
$$

where: $F_{s h, k}-$ shading factor of external obstacles for the window surface $A_{w d, k} ; F_{s h, g l, k}$ - shading factor of movable shading appliances for the window surface $A_{w d, k}$ (mechanically and electrically controlled external and internal Venetian blinds and similar equipment); $F_{F, k}$ - ratio of the projected frame area to the overall projected area of the glazed element; $I_{\text {sol, },}$ - the mean global solar radiation over the time step of calculation onto appropriate element $k$ with the given orientation and tilt angle, $\mathrm{W} / \mathrm{m}^{2}$.

Solar energy flow $\Phi_{\text {sol, lw, }}, \mathrm{W}$, absorbed by the inside surfaces of the building after passing through the transparent elements of the building envelope and transformation into long wave thermal energy, could be calculated at every time step $t$ as follows:

$$
\Phi_{s o l, l w, t}=\alpha_{s w, s i} \cdot \Phi_{s o l, s w, t},
$$

where: $\alpha_{s w, s i}$ - mean solar radiation absorption coefficient of internal surfaces of the building.

The use of solar radiation absorption coefficient $\alpha_{s w, s i}$ of inside surfaces of the building and the mechanism of transformation of short wave thermal radiation into long wave thermal radiation energy have not yet been regarded in the calculation methods of energy demand for heating or cooling of the buildings (LST EN ISO 13790 2008; Nielsen, Svendsen 2005) nor in the research results (Yohanis, Norton 1999; Kalema et al. 2008; Josikalo, Kurnitski 2007; Zinzi et al. 2008; Carmody et al. 2004; Corrado, Fabrizio 2007; Orosa, Oliveira, 2010; Sjösten et al. 2003; Šeduikyte, Paukštys 2008). Perhaps, by this reason the difference in the values of solar heat gains obtained by the calculation on the basis of LST EN ISO 13790 (2008) and experimental studies is observed; according to Kalema et al. (2008), the solar gain utilization factor is too low for very light buildings having no massive surfaces; as Josikalo and Kurnitski (2007) state, in the 2004 version of the standard LST EN ISO 13790, the numerical parameters of heat gains are reasonably applicable for residential buildings, but not for office buildings. Josikalo and Kurnitski (2007) claim that the evaluation methods are acceptable, especially for the existing buildings, and according to Motuziene and Juodis (2010) to office buildings as well, but the results obtained show the annual best values when windows are installed in northern wall. Such item is disputable.

\subsection{Hourly calculation method of building heat gains. Energy demand for heating the buildings}

Time step at the calculation is assumed to be equal to one hour, i.e. $\Delta \mathrm{t}=1 \mathrm{~h}$. It is considered that during this time step heat transfer settles into a steady-state mode. The required thermal energy flow at every time step $t$ for heating the building is determined as follows:

$$
\begin{gathered}
\Phi_{H, t}=H_{t o t} \cdot\left(\theta_{i, t}-\theta_{e, t}\right)-\Phi_{\mathrm{int}, t}+\Phi_{r, t}-\Phi_{s o l, a b, t} \\
H_{t o t}=H_{t r}+H_{v e} \\
H_{t r}=\sum\left(U_{k} \cdot A_{k}\right) \\
H_{v e}=\rho_{a} \cdot c_{a} \cdot \sum\left(n \cdot V \cdot b_{v e}\right)
\end{gathered}
$$


where: $\theta_{i, t}$ and $\theta_{e, t}$ - respectively, indoor and outdoor air temperature at time step $t,{ }^{\circ} \mathrm{C} ; H_{t o t}-$ total heat transfer coefficient of the building, W/K; $H_{t r}-$ transmission heat transfer coefficient of the building, W/K; $H_{v e}-$ ventilation heat transfer coefficient of the building, W/K; $n$ - mean air change rate for ventilation, $\mathrm{h}^{-1} ; V$ - inside volume of the building, $\mathrm{m}^{3} ; b_{v e}$-temperature adjustment factor if the supplied air temperature is not equal to the temperature of external environment; this value will be determined in accordance with LST EN ISO 13790 (2008); $\rho_{a} \cdot c_{a}$ - heat capacity of air per volume, $\rho_{a} \cdot c_{a}=$ $0.34 \mathrm{Wh} /\left(\mathrm{m}^{3} \cdot \mathrm{K}\right)$.

For the determination of short wave solar gains admitted into the building, the following presumptions are made:

- all solar radiation absorption coefficients $\alpha_{s w}$ are the same for all inside surfaces;

- solar energy flow $\Phi_{\text {sol.sw }}$ impacts are even to all inside surfaces, therefore, the temperature changes of all surfaces are the same;

- external surface temperature $\theta_{m, \text { surf }}$ of the effective thermal capacity layer $d$ varies in the rooms (LST EN ISO 13790 2008; Carmody et al. 2004), but the temperature of the opposite internal plane $\theta_{m, i}$ bordering this layer stays constant (see Fig. 1);

- temperature profile between the outer surface and opposite internal plane bordering the effective thermal capacity layer is considered to be linear (see Fig. 1);

- thermal energy flow $\Phi_{m}$ absorbed/released by effective heat capacity of the building during the time step $\Delta \mathrm{t}$ is proportional to the change of mean temperature $\theta_{d}$ of heat capacity layer (see Eq. (12));

- initial time step $t$ corresponds to the beginning of the day.

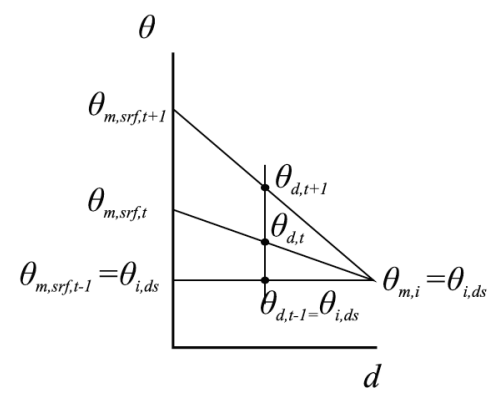

Fig. 1. Scheme of temperature change in effective heat capacity layer at various moments of time

Thermal energy flow $\Phi_{m, t}$ absorbed (see Fig. 2) or released (see Fig. 3) by the effective heat capacity layer of the rooms can be calculated at every time step $t$ :

$$
\begin{aligned}
& \Phi_{m, t}=C_{m} / \Delta t \cdot\left(\theta_{m, d, t}-\theta_{m, d, t-1}\right)= \\
& C_{m} / \Delta t \cdot\left(\frac{\theta_{m, \text { surf }, t}+\theta_{m, i, t}}{2}-\frac{\theta_{m, \text { surf }, t-1}+\theta_{m, i, t}}{2}\right)= \\
& C_{m} / \Delta t \cdot 0,5 \cdot\left(\theta_{m, \text { surf }, t}-\theta_{m, \text { surf }, t-1}\right),
\end{aligned}
$$

where: $C_{m}$ - effective heat capacity of the building, $\mathrm{Wh} / \mathrm{K}$; for buildings with high effective heat capacity $C_{m}=102.8 \cdot A_{f} \quad \mathrm{Wh} / \mathrm{K}$, with very low capacity $C_{m}=22.2 \cdot A_{f} \mathrm{Wh} / \mathrm{K}(\mathrm{LST}$ EN ISO 137902008$)$.

With the enlargement of solar thermal energy flow (Fig. 2) admitted into the building, the thermal balance of flows settles at the outer surface of the effective heat capacity layer of the building $\Phi_{m-i, t}=\Phi_{\text {sol. } . w_{,}, t}-\Phi_{m, t}$, and with the decrease of the admitted solar energy flow (Fig. 3), the thermal balance $\Phi_{m-i, t}=\Phi_{\text {sol.lw,t }}+\Phi_{m, t}$ also settles at this surface.

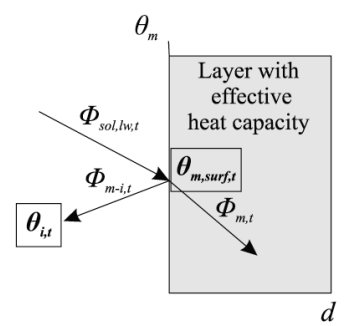

Fig. 2. Scheme of thermal flows when solar energy flow increases

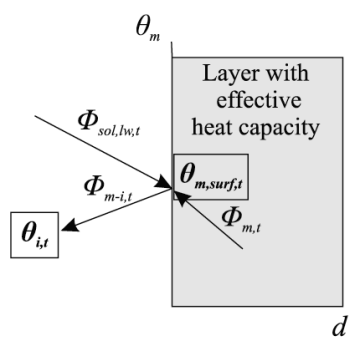

Fig. 3. Scheme of thermal flows when solar energy flow decreases

As the solar energy flow admitted into the rooms increases, the indoor surface temperatures are increased too. If heat gains are sufficient to heat the building, the internal surfaces of the rooms have to emit such thermal energy flow which is required to heat the building up to $\theta_{i, H, d s}$ indoor temperature. Until the thermal energy flow from the surfaces $\Phi_{m-i, t}$ is less than required to heat the building:

$$
\Phi_{H, t} \geq \Phi_{m-i, t}, \quad \theta_{i, t}=\theta_{i, H, d s},
$$

i.e., until the internal surfaces transmit the thermal energy into the ambience with the design indoor air temperature $\theta_{i, H, d s}$, the emitted energy flow from them at every time step $t, t+1, t+2 \ldots$ can be calculated as follows:

$$
\Phi_{m-i, t}=h_{s i} \cdot A_{m, t o t} \cdot\left(\theta_{m, s u r f, t}-\theta_{i, H, d s}\right),
$$

where: $A_{m, t o t}$ - the total area of internal surfaces of the rooms, $\mathrm{m}^{2}$ could be taken as $A_{m, t o t}=4.5 \cdot A_{f}$ (LST EN ISO 13790 2008).

Flow $\Phi_{m-i, t}$ from Eq. (3) is calculated in the following manner: the temperatures of the surfaces are calculated at every time step $t$ according to Eqs. (16) and (19) and the flows into the rooms with temperature $\theta_{i, H, d s}$ are calculated according to Eqs. (14) and (21), i.e. in Eq. (21) the 
temperature is taken as $\theta_{i, t+j}=\theta_{i, H, d s}$. At every time step $t$, $\Phi_{m-i, t}$ corresponds to the higher values calculated according to Eqs. (14) and (21).

If $\Phi_{H, t} \geq \Phi_{m-1, t}$, then at the initial time step which corresponds to the beginning of the day, the thermal exchange balance equation for outer surfaces of effective heat capacity layers of the rooms could be expressed in the following manner:

$$
\begin{aligned}
& h_{s i} \cdot A_{m, t o t} \cdot\left(\theta_{m, \text { surf }, t}-\theta_{i, H, d s}\right)+ \\
& C_{m} / \Delta t \cdot 0,5 \cdot\left(\theta_{m, \text { surf }, t}-\theta_{m, \text { surf }, t-1}\right)=\Phi_{\text {sol }, l w, t},
\end{aligned}
$$

and temperature $\theta_{m, s u r f, t}$ could be calculated from Eq. (15):

$$
\begin{aligned}
& \theta_{m, \text { surf }, t}= \\
& \frac{\Phi_{\text {sol }, l w, t}+0,5 \cdot C_{m} / \Delta t \cdot \theta_{m, \text { surf }, t-1}+h_{s i} \cdot A_{m, t o t} \cdot \theta_{i, H, d s}}{h_{s i} \cdot A_{m, t o t}+0,5 \cdot C_{m} / \Delta t}
\end{aligned}
$$

where: $\theta_{\mathrm{m}, \text { surf }, \mathrm{t}-1}=\theta_{\mathrm{i}, \mathrm{H}, \mathrm{ds}}$.

When heat flow from the internal surfaces of the rooms becomes higher than it is required for heating, the inside air temperature begins to increase. In this case the surfaces transmit thermal energy flow into the ambience with enlarged air temperature of the rooms, in other words, the condition of Eq. (13) is not fulfilled. It is considered that this occurs at the time step $t+j$, and the temperature of the rooms is $\theta_{i, t+j}$. At that moment such balance of thermal flows settles down:

- balance of heat exchange between the heat flow required to heat the rooms up to the temperature $\theta_{i, t^{+j}}$ and the flow from the internal surfaces of the rooms into the rooms with $\theta_{i, t+j}$ temperature:

$$
\begin{aligned}
& H_{t o t} \cdot\left(\theta_{i, t+j}-\theta_{e, t+j}\right)-\Phi_{\mathrm{int}, t+j}+\Phi_{r, t+j}-\Phi_{\text {sol }, a b, t+j}= \\
& h_{s i} \cdot A_{m, t o t} \cdot\left(\theta_{m, \text { surf }, t+j}-\theta_{i, t+j}\right)
\end{aligned}
$$

- balance of heat exchange between the heat flows from the internal surfaces plus effective heat capacity layer and solar long wave thermal flow from internal surfaces:

$$
\begin{aligned}
& h_{s i} \cdot A_{m, t o t} \cdot\left(\theta_{m, \text { surf }, t+j}-\theta_{i, t+j}\right)+C_{m} / \Delta t \cdot 0,5 . \\
& \left(\theta_{m, \text { surf }, t+j}-\theta_{m, \text { surf }, t-1+j}\right)=\Phi_{s o l, l w, t+j} .
\end{aligned}
$$

The Eqs. (17) and (18) comprise an equation system and its solution enables calculating the temperatures of internal surfaces $\theta_{m, \text { sur }, t+j}$ and indoor air temperatures $\theta_{i, t+j}$ of the rooms at the time step $t+j$ :

$$
\begin{aligned}
& \theta_{m, s u r f, t+j}=\left[\left(H_{t o t}+h_{s i} \cdot A_{m, t o t}\right) \cdot \Phi_{s o l, l w, t+j}+h_{s i} .\right. \\
& A_{m, t o t} \cdot H_{t o t} \cdot \theta_{e, t+j}+h_{s i} \cdot A_{m, t o t} \cdot\left(\Phi_{\mathrm{int}, t+j}-\Phi_{r, t+j}+\right. \\
& \left.\Phi_{s o l, a b, t+j}\right)+0,5 \cdot\left(H_{t o t}+h_{s i} \cdot A_{m, t o t}\right) \cdot C_{m} / \Delta t \cdot \\
& \left.\theta_{m, \text { surf }, t-1+j}\right] /\left[\left(H_{t o t}+h_{s i} \cdot A_{m, t o t}\right) \cdot h_{s i} \cdot A_{m, t o t}-\right. \\
& \left.h_{s i}^{2} \cdot A_{m, t o t}^{2}+0,5 \cdot\left(H_{t o t}+h_{s i} \cdot A_{m, t o t}\right) \cdot C_{m} / \Delta t\right] ;
\end{aligned}
$$

$$
\begin{aligned}
& \theta_{i, t+j}= \\
& \frac{h_{s i} \cdot A_{m, t o t} \cdot \theta_{m, s u f, t+j}+H_{t o t} \cdot \theta_{e, t+j}+\Phi_{\text {int }, t+j}-\Phi_{r, t+j}+\Phi_{s o l, a b, t+j}}{H_{t o t}+h_{s i} \cdot A_{m, t o t}} .
\end{aligned}
$$

By knowing the internal surface temperature $\theta_{m, s u r f, t+j}$ of the rooms at the time step $t+j$ and the indoor air temperature $\theta_{i, t+j}$ of the rooms, the heat flow between the internal surfaces and indoor air could be calculated as follows:

$$
\Phi_{m-i, t+j}=h_{s i} \cdot A_{m, t o t} \cdot\left(\theta_{m, \text { surf }, t+j}-\theta_{i, t+j}\right) .
$$

The heat flow from the heating system $\Phi_{H, n d, t}$, which is required to maintain the design indoor air temperature $\theta_{i, H, d s}$, could be calculated in such manner:

$$
\begin{aligned}
& \text { if } \theta_{i, t}=\theta_{i, H, d s}, \Phi_{H, n d, t}=\Phi_{H, t}-\Phi_{m-i, t}, \\
& \text { if } \theta_{i, t}>\theta_{i, H, d s} \Phi_{H, n d, t}=0 .
\end{aligned}
$$

Total daily amount of energy $Q_{H, n d, d a y}$, required to heat the rooms up to the design indoor air temperature $\theta_{i, H, d s}$, is calculated by the following formula:

$$
Q_{H, n d, d a y}=\sum_{t=1}^{24}\left(\Phi_{H, n d, t} \cdot \Delta t\right) .
$$

The total rate of heat gains $\Phi_{g n, H, t}$ at every time step $t$ required to heat the rooms up to the design indoor air temperature $\theta_{i, H, d s}$, is calculated in such manner:

$$
\begin{gathered}
\text { if } \theta_{i, t}=\theta_{i, H, d s}, \\
\Phi_{g n, H, t}=\Phi_{m-i, t}+\Phi_{\mathrm{int}, t}-\Phi_{r, t}+\Phi_{s o l, a b, t}, \\
\text { if } \theta_{i, t}>\theta_{i, H, d s}, \Phi_{g n, H, t}=\Phi_{H, t} .
\end{gathered}
$$

The following formula is used for calculating the total daily amount of heat gains $Q_{g n, H, d a y}$, required to heat the rooms up to the design indoor air temperature $\theta_{i, H, d s}$ :

$$
Q_{g n, H, d a y}=\sum_{t=1}^{24}\left(\Phi_{g n, H, t} \cdot \Delta t\right) \text {. }
$$

\subsection{Hourly calculation method of building heat gains. Energy demand for cooling the building}

The calculation of energy demand for cooling is similar to the calculation method of energy demand for heating the building. First of all, the design indoor air temperature $\theta_{i, C, d s}$ is chosen, i.e. the maximal allowable indoor temperature. Usually for the calculations of energy needed for cooling it is considered to be $26^{\circ} \mathrm{C}$. The calculations are performed as follows:

- indoor air temperature $\theta_{i, t}$ at every time step $t$ is calculated according to Eqs. (13)-(19). If the condition of Eq. (13) is fulfilled, this temperature will be equalled to $\theta_{i, C, d s}$, if not - to the temperature $\theta_{i, t+j}$;

- if $\theta_{i, t} \leq \theta_{i, C, d s}$, there is no need to cool the rooms; 
- if $\theta_{i, t}>\theta_{i, C, d s}$, the rooms ought to be cooled, and the required cool flow at every time step $t$ is calculated using the following formula:

$$
\Phi_{C, n d, t}=H_{t o t} \cdot\left(\theta_{i, t}-\theta_{i, C, d s}\right) .
$$

Total daily amount of cooling energy $Q_{g n, C, d a y}$, required to cool the rooms down to the design indoor air temperature $\theta_{i, C, d s}$, is calculated in such manner:

$$
Q_{C, n d, d a y}=\sum_{t=1}^{24}\left(\Phi_{C, n d, t} \cdot \Delta t\right)
$$

\section{The analysis of calculation results obtained by various methods}

The analysis of calculation results acquired by the described hourly calculation method and the hourly and monthly calculation methods was performed. The calculation model was chosen on the basis of extreme impact of heat gains to thermal energy demand for heating or cooling. The model was constructed as a part of the building with only one external wall. The whole area of this wall was occupied by windows. Adjacent rooms of this part of the building kept up the same temperature as in the modelled rooms. In other words, there was no heat exchange at every considered time step between the modelled and the adjacent rooms.

\subsection{Data of the chosen model}

Data on the rooms: floor area $A_{f}=100 \mathrm{~m}^{2}(10 \times 10 \mathrm{~m})$; height $2.5 \mathrm{~m}$; volume $V=100 \mathrm{~m}^{3}$. Data on the windows: vertical; South oriented; area $A_{w, k}=A_{s o l, k}=25 \mathrm{~m}^{2} ; U=$ $1.3 \mathrm{~W} /\left(\mathrm{m}^{2} \cdot \mathrm{K}\right) ; \varepsilon_{l w, e . s .}=0.9 ; \alpha_{s w, e . s .}=0.12 ; F_{r, k}=0.5 ; F_{s h, k}=1$; $F_{s h, g l, k}=1 ; F_{f, k}=0.2 ; g_{g l, n, k}=0.5$. Other data: $h_{s e, c}=$ $25 \mathrm{~W} /\left(\mathrm{m}^{2} \cdot \mathrm{K}\right) ; \quad h_{s i}=7.7 \quad \mathrm{~W} /\left(\mathrm{m}^{2} \cdot \mathrm{K}\right) ; \quad \alpha_{s w, i . s}=0.6 ; C_{m}=$ $10280 \mathrm{Wh} / \mathrm{K} ; n=0.5 \mathrm{~h}^{-1} ; b_{v e}=1$; natural ventilation; $\theta_{i, H, d s}=20{ }^{\circ} \mathrm{C} ; \theta_{e, t}=5.5{ }^{\circ} \mathrm{C} ; g_{\text {int }, t}=$ const $=1.2 \mathrm{~W} / \mathrm{m}^{2}$; $\Delta \theta_{e r}=10 \mathrm{~K}$; according to Eq. (3) calculated $\Phi_{r}=$ const $=$ $22.31 \mathrm{~W}$. The calculation of the global solar radiation $I_{\text {sol }, k, t}$ in April according to the suggested hourly calculation method is based on the Lithuanian climate data. They are presented in Table 1 below together with the calculation results. For the calculations according to the method of (LST EN ISO 137902008$), I_{s o l, k}=113 \mathrm{~W} / \mathrm{m}^{2}$.

\subsection{Energy demand for heating. The analysis of results acquired by the presented hourly calculation method and the hourly method of LST EN ISO 13790 (2008)}

The method presented in this article uses the monthly mean hourly solar radiation data as well as the mean hourly data of other heat gains. Monthly mean heat gains or indices of energy use are established according to the calculation regarding each day of the month (e.g. 30 days of April). In case of our calculation model, the calculation

\begin{tabular}{|c|c|c|c|c|c|c|c|c|c|}
\hline \multicolumn{2}{|c|}{ Equation no: } & \multirow{2}{*}{$\frac{(4)}{\frac{\Phi_{s o l, a b, t}}{W}}$} & \multirow{2}{*}{$\frac{(6)}{\frac{\Phi_{s o l, s w, t}}{W} ;}$} & \multirow{2}{*}{$\frac{(7)}{\frac{\Phi_{s o l, l w, t}}{W}}$} & \multirow{2}{*}{ 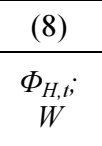 } & \multirow{2}{*}{$\begin{array}{c}(13),(16),(19) \\
Q_{m, \text { surf }, t} \text { or } \\
Q_{m, \text { surf }, t+j} ;{ }^{\circ} \mathrm{C}\end{array}$} & \multirow{2}{*}{$\frac{(13),(20)}{Q_{i, t} \text { or } Q_{i, t+j} ;{ }^{\circ} \mathrm{C}}$} & \multirow{2}{*}{$\frac{(22)}{\frac{\Phi_{H, n d, t} ;}{W}}$} & \multirow{2}{*}{$\frac{(24)}{\underset{\Phi_{g n, H, t}}{W}}$} \\
\hline $\begin{array}{c}\text { Time, } \\
\mathrm{h}\end{array}$ & $\begin{array}{l}I_{s o l, k, t} \\
W / m^{2}\end{array}$ & & & & & & & & \\
\hline 1 & & 0.00 & 0 & 0 & 990 & 20.00 & 20.00 & 990 & 98 \\
\hline 2 & & 0.00 & 0 & 0 & 990 & 20.00 & 20.00 & 990 & 98 \\
\hline 3 & & 0.00 & 0 & 0 & 990 & 20.00 & 20.00 & 990 & 98 \\
\hline 4 & & 0.00 & 0 & 0 & 990 & 20.00 & 20.00 & 990 & 98 \\
\hline 5 & 2 & 0.26 & 18 & 11 & 990 & 20.00 & 20.00 & 985 & 102 \\
\hline 6 & 14 & 1.85 & 126 & 76 & 988 & 20.01 & 20.00 & 955 & 133 \\
\hline 7 & 43 & 5.68 & 387 & 232 & 984 & 20.03 & 20.00 & 871 & 217 \\
\hline 8 & 120 & 15.86 & 1080 & 648 & 974 & 20.09 & 20.00 & 646 & 442 \\
\hline 9 & 209 & 27.63 & 1881 & 1129 & 962 & 20.19 & 20.00 & 312 & 776 \\
\hline 10 & 294 & 38.87 & 2646 & 1588 & 951 & 20.31 & 20.34 & 0 & 951 \\
\hline 11 & 343 & 45.35 & 3087 & 1852 & 944 & 20.48 & 20.52 & 0 & 944 \\
\hline 12 & 368 & 48.65 & 3312 & 1987 & 941 & 20.68 & 20.71 & 0 & 941 \\
\hline 13 & 369 & 48.78 & 3321 & 1993 & 941 & 20.88 & 20.90 & 0 & 941 \\
\hline 14 & 332 & 43.89 & 2988 & 1793 & 946 & 21.03 & 21.05 & 0 & 946 \\
\hline 15 & 268 & 35.43 & 2412 & 1447 & 954 & 21.12 & 21.13 & 0 & 954 \\
\hline 16 & 194 & 25.65 & 1746 & 1048 & 964 & 21.12 & 21.13 & 0 & 964 \\
\hline 17 & 108 & 14.28 & 972 & 583 & 976 & 21.03 & 21.04 & 0 & 976 \\
\hline 18 & 38 & 5.02 & 342 & 205 & 985 & 20.87 & 20.88 & 0 & 985 \\
\hline 19 & 12 & 1.59 & 108 & 65 & 988 & 20.69 & 20.70 & 0 & 988 \\
\hline 20 & & 0.00 & 0 & 0 & 990 & 20.49 & 20.51 & 0 & 990 \\
\hline 21 & & 0.00 & 0 & 0 & 990 & 20.30 & 20.32 & 0 & 990 \\
\hline 22 & & 0.00 & 0 & 0 & 990 & 20.18 & 20.00 & 370 & 717 \\
\hline 23 & & 0.00 & 0 & 0 & 990 & 20.11 & 20.00 & 620 & 468 \\
\hline 24 & & 0.00 & 0 & 0 & 990 & 20.06 & 20.00 & 769 & 319 \\
\hline & & & & Total: & 23397 & & Total: & 9486 & 15134 \\
\hline
\end{tabular}

Table 1. Calculation results of indices related to the thermal energy for heating 


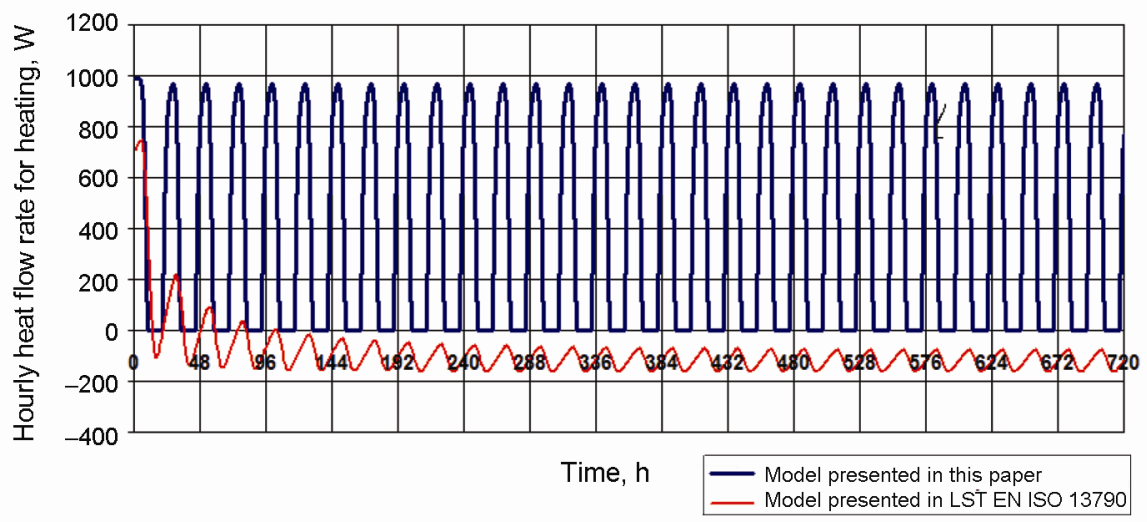

Fig. 4. Hourly heat flow rate required for heating in April, calculation results applying two different hourly calculation methods

results during the month, in comparison with the results of the first day of the month (Table 1), vary only slightly. The results of the calculation for heating energy flow demand $\Phi_{H, n d, t}$ during each day of April are presented in Fig. 4, as well as the results acquired according to the LST EN 13790 (2008) hourly method.

The LST EN 13790 (2008) method does not specify whether one- or several-day calculations should be considered when establishing the values of hourly energy demand during the day. Therefore, aiming at a better analysis of this method, the heat flow energy demand for heating the rooms $\Phi_{H, n d, t}$ was calculated during the same period of 30 days. It was difficult to evaluate the results of the calculation, as they vary from $700 \mathrm{~W}$ heating energy flow demand to about $100 \mathrm{~W}$ cooling energy flow demand during the first few days. For the comparison of results acquired by these two different calculation methods the results of the first few days of the month were used.

The first day results calculated according to the LST EN 13790 (2008) method show the $7169 \mathrm{Wh} /$ day amount of heating energy demand. This result is close to the result acquired by the hourly calculation method presented in this paper ( $9486 \mathrm{Wh} /$ day). The differences in the calcu- lation results for the following days acquired by the mentioned calculation methods markedly grow. It is shown in detail in Fig. 5 where the calculation results of the first three days are displayed. Data in Fig. 6 expressing the results of our calculation method from 0 to 24 hour correspond to the results given in Table 1 .

The LST EN 13790 (2008) method uses daily mean solar radiation data for calculations, but indoor temperature during the day is calculated by hours and varies in a considerably wide range. The calculation results of the indoor temperature calculated by our and LST EN 13790 (2008) methods are presented in Fig. 6. The difference between the calculation results is not significant, but in accordance with the data presented earlier, it is seen that it makes an essential impact on the calculation results of energy demand for heating and cooling of the rooms. The energy demand for heating diminishes with every following day. According to the calculation results from Fig. 6, presenting the LST EN 13790 (2008) calculation method, the indoor temperature is increasing and energy demand for heating is decreasing every day (Figs. 4 and 5). This shows that the LST EN 13790 (2008) method has to apply additional conditions not described by this method in order to avoid divergences of the calculation results.

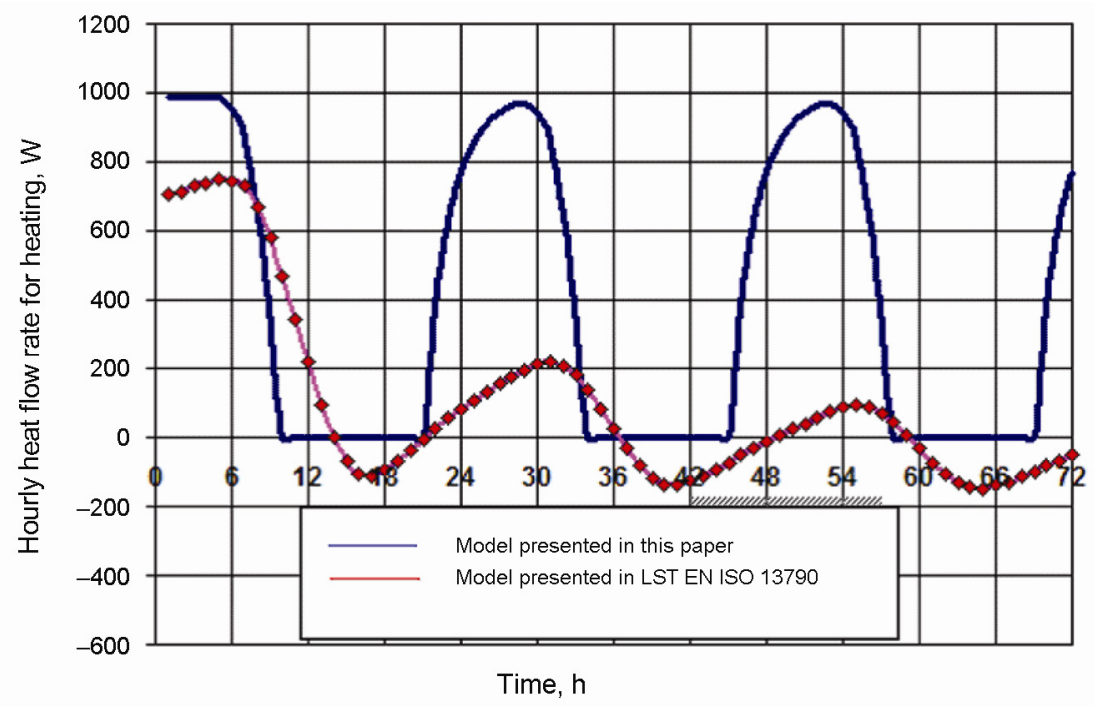

Fig. 5. Hourly heat flow rate required for heating in April, calculation results of the first days applying two different hourly calculation methods 


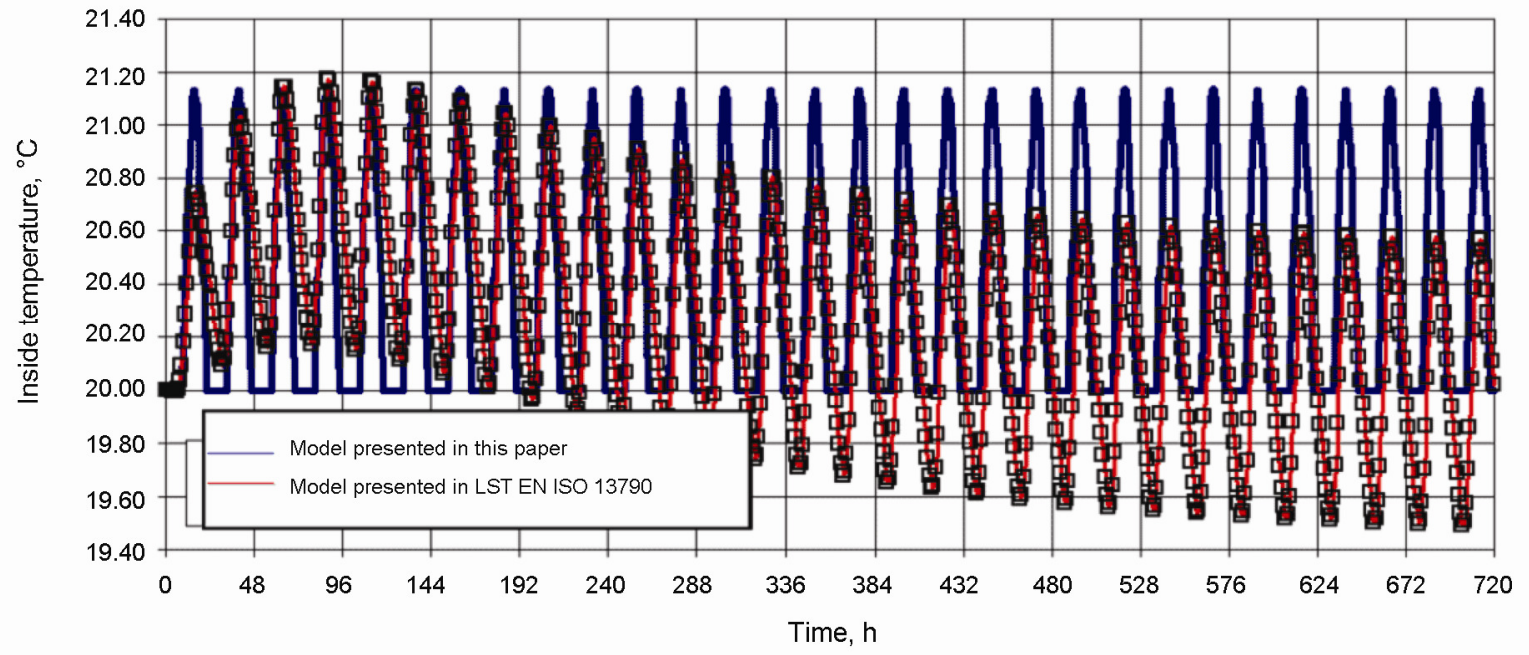

Fig. 6. Inside temperature in April, calculation results applying two different hourly calculation methods

\subsection{Energy demand for heating. The analysis of results acquired by the presented hourly calculation method and the LST EN ISO 13790 (2008) monthly calculation method}

The results acquired using the LST EN 13790 monthly calculation method are the following: the sum of transmission and ventilation heat losses during the day makes up $26100 \mathrm{Wh} /$ day; heat gains $26674 \mathrm{Wh} /$ day; $\tau_{H, 0}=15$; $\alpha_{\mathrm{H}, 0}=1 ; \tau=137.04 ; \alpha_{H}=10.14 ; \gamma_{H}=1.02 ; \eta_{H, g n}=0.90$; the amount of heat gains utilized for heating of the building makes up 26674.0.9 $=24006 \mathrm{Wh} /$ day; energy demand for heating of the building makes up $26100-24006=$ $2094 \mathrm{Wh} /$ day. The calculation result $(2094 \mathrm{Wh} /$ day $)$ is more than 4 times lesser than the monthly mean result obtained by our hourly calculation method ( $9486 \mathrm{Wh} /$ day). Moreover, this result $(2094 \mathrm{Wh} /$ day) differs from the first day result $(7169 \mathrm{Wh} /$ day $)$ obtained by the LST EN ISO 13790 (2008) hourly method calculation too.

The difference between our and LST EN 13790 (2008) monthly methods emerges due to the differences in estimation of solar heat gains inside the rooms:

- monthly method presented in LST EN ISO 13790 (2008) assumes that the whole amount of solar radiation admitted indoor turns into long wave thermal energy. In other words, it is assumed that solar radiation absorption coefficient of inside surfaces of the rooms is $\alpha_{s w}=1$. When calculating energy indices for heating, the method takes into account the fact that solar heat gains may be higher than the heat losses in certain times of the day and at these times heating of the rooms is not required. It means that all solar heat gains are not used to heat the rooms, i.e., it is assumed that only a $\eta_{H, g n}$ part of solar heat gains is related to the energy demand for heating;

- the hourly calculation method presented in this paper assumes that only a part $\alpha_{s w}$ of solar heat gains admitted indoor is used for heating the rooms, i.e., this part is expressed by solar radia- tion absorption coefficient of indoor surfaces. Energy indices for heating of the building are calculated according to Eqs. (24) and (25) for each hour of the day and the hourly indoor and outdoor temperatures are taken into account. Therefore, there is no need to apply any correctives to the calculation results of solar heat gains.

For more particular analysis of both methods mentioned above additional calculations using different monthly mean outdoor temperatures were carried out. It was assumed that solar radiation absorption coefficient of indoor surfaces is the same as in the LST EN 13790 (2008) method, i.e., $\alpha_{s w}=1$ according to our hourly method. In all calculations the data on solar radiation were taken from Table 1. The calculation results are given in Table 2. This table also contains the results calculated according to the hourly method of LST EN 13790 (2008).

The results in Table 2 show that the results of our hourly method are much closer to the results of the LST EN 13790 monthly method than to the results of the LST EN 13790 hourly method.

\subsection{Energy demand for cooling. The analysis of results acquired by the presented hourly calculation method and LST EN ISO 13790 (2008) hourly method}

For summertime calculations the data of July from Lithuanian climate database were used, i.e., $\theta_{i, C, d s}=26^{\circ} \mathrm{C}$; $\theta_{e, t}=16.72^{\circ} \mathrm{C}$, the other income data are the same as for the calculations of heating energy demand. The monthly mean of July and the data on solar radiation $I_{s o l, k, t}$ are given in Table 3 below together with the calculation results obtained by our hourly calculation method. For the calculations according to the LST EN ISO 13790 (2008) method, $I_{s o l, k}=122 \mathrm{~W} / \mathrm{m}^{2}$.

The calculation results of the required cooling energy flow $\Phi_{C, n d, t}$ on each day of July are presented in Fig. 7. The data expressing the results of our calculation method from 0 to 24 hour correspond to the results in Table 3 . 
According to the LST EN 13790 (2008) hourly method, the calculation results reflecting the first few days of July are varying from $400 \mathrm{~W}$ energy flow for heating to about $600 \mathrm{~W}$ energy flow for cooling. To compare the results of different calculation methods the calculation results of the first few days were used. The first day calculation results according to the LST EN 13790 (2008) hourly method shows cooling energy demand of $1743 \mathrm{Wh} /$ day. This result is close to the result of the first day cooling energy demand calculated by our hourly calculation method (1412 Wh/day). Our method gives value of $2109 \mathrm{Wh} /$ day as monthly mean cooling energy demand. The differences in calculation results by the use of these different methods during the following days of July grow markedly.

\subsection{Energy demand for cooling. The analysis of results acquired by the presented hourly calculation method and LST EN ISO 13790 (2008) monthly method}

The results acquired using the LST EN 13790 (2008) monthly calculation method are the following: the sum of transmission and ventilation heat losses during the day makes up $16704 \mathrm{Wh} /$ day; heat gains $28582 \mathrm{Wh} /$ day; $\tau_{C, 0}=15 ; \alpha_{C, 0}=1 ; \tau=137,04 ; \alpha_{C}=10.14 ; \gamma_{C}=1.71$; $\eta_{C, l s}=0.998$

Taking into account the dimensionless utilization factor for heat losses $\eta_{C, l s}$, the sum of transmission and ventilation heat losses during the day makes up 16704.0.998= $16670 \mathrm{Wh} /$ day; energy demand for cooling the building makes up $28582-16670=11912 \mathrm{Wh} /$ day.

Table 2. Energy demand for heating, calculation results by three different calculation methods at various outdoor temperatures

Monthly mean temperature, ${ }^{\circ} \mathrm{C}$

\begin{tabular}{|c|c|c|c|c|c|}
\hline & -10 & 0 & 5.5 & 10 & 15 \\
\hline $\begin{array}{l}\text { Amount of daily mean energy demand for heating } Q_{H, n d, d a y} \text { according to } \\
\text { our method (monthly mean value), } \mathrm{Wh} / \text { day }\end{array}$ & 27142 & 9922 & 1179 & 146 & 56 \\
\hline $\begin{array}{l}\text { Amount of daily mean energy demand for heating } Q_{H, n d, \text { day }} \text { according to } \\
\text { the LST-EN ISO } 13790 \text { hourly method (first day value), Wh/day }\end{array}$ & 30811 & 15558 & 7169 & 305 & -7322 \\
\hline Utilization factor for heat gains $\eta_{H, g n}$ & 1 & 0.99 & 0.9 & 0.67 & 0.34 \\
\hline $\begin{array}{l}\text { Amount of daily mean energy demand for heating } Q_{H, n d, d a y} \text { according to } \\
\text { the LST-EN ISO } 13790 \text { monthly method, } \mathrm{Wh} / \text { day }\end{array}$ & 27336 & 9669 & 2094 & 110 & 0,1 \\
\hline
\end{tabular}

Table 3. Calculation results of indices related to thermal energy for cooling

\begin{tabular}{|c|c|c|c|c|c|c|c|c|}
\hline \multicolumn{2}{|c|}{ Equation no: } & (4) & (6) & (7) & (8) & $(13),(16),(19)$ & $(13),(20)$ & (26) \\
\hline$\underset{\mathrm{h}}{\mathrm{Time}}$ & $\begin{array}{l}I_{s o l, k, t} ; \\
W / m^{2}\end{array}$ & $\begin{array}{c}\Phi_{s o l, a b, t} \\
W\end{array}$ & $\begin{array}{c}\Phi_{s o l, s w, t} \\
W\end{array}$ & $\begin{array}{c}\Phi_{s o l, l w, t} \\
W\end{array}$ & $\underset{W}{\Phi_{H, l} ;}$ & $\begin{array}{c}Q_{m, \text { surf }, t} \text { or } \\
Q_{m, \text { surf }, t+j},{ }^{\circ} \mathrm{C}\end{array}$ & $\begin{array}{c}Q_{i, t} \text { or } \\
Q_{i, t+j},{ }^{\circ} \mathrm{C}\end{array}$ & $\begin{array}{l}\Phi_{C, n d, l} ; \\
\quad W\end{array}$ \\
\hline 1 & & 0.00 & 0 & 0 & 598 & 26.00 & 26.00 & 0.0 \\
\hline 2 & & 0.00 & 0 & 0 & 598 & 26.00 & 26.00 & 0.0 \\
\hline 3 & & 0.00 & 0 & 0 & 598 & 26.00 & 26.00 & 0.0 \\
\hline 4 & 3 & 0.40 & 27 & 16 & 598 & 26.00 & 26.00 & 0.0 \\
\hline 5 & 20 & 2.64 & 180 & 108 & 596 & 26.01 & 26.00 & 0.0 \\
\hline 6 & 47 & 6.21 & 423 & 254 & 592 & 26.04 & 26.00 & 0.0 \\
\hline 7 & 76 & 10.05 & 684 & 410 & 588 & 26.07 & 26.00 & 0.0 \\
\hline 8 & 131 & 17.32 & 1179 & 707 & 581 & 26.12 & 26.00 & 0.0 \\
\hline 9 & 218 & 28.82 & 1962 & 1177 & 569 & 26.24 & 26.27 & -20.4 \\
\hline 10 & 298 & 39.40 & 2682 & 1609 & 559 & 26.44 & 26.47 & -35.3 \\
\hline 11 & 346 & 45.74 & 3114 & 1868 & 553 & 26.69 & 26.72 & -53.7 \\
\hline 12 & 362 & 47.86 & 3258 & 1955 & 550 & 26.95 & 26.97 & -73.0 \\
\hline 13 & 357 & 47.20 & 3213 & 1928 & 551 & 27.21 & 27.22 & -91.5 \\
\hline 14 & 326 & 43.10 & 2934 & 1760 & 555 & 27.42 & 27.43 & -107.3 \\
\hline 15 & 274 & 36.22 & 2466 & 1480 & 562 & 27.58 & 27.58 & -118.8 \\
\hline 16 & 206 & 27.23 & 1854 & 1112 & 571 & 27.66 & 27.66 & -124.8 \\
\hline 17 & 126 & 16.66 & 1134 & 680 & 582 & 27.66 & 27.66 & -124.4 \\
\hline 18 & 75 & 9.92 & 675 & 405 & 588 & 27.61 & 27.60 & -120.1 \\
\hline 19 & 43 & 5.68 & 387 & 232 & 593 & 27.51 & 27.51 & -113.5 \\
\hline 20 & 16 & 2.12 & 144 & 86 & 596 & 27.40 & 27.40 & -104.9 \\
\hline 21 & 2 & 0.26 & 18 & 11 & 598 & 27.27 & 27.27 & -95.3 \\
\hline 22 & & 0.00 & 0 & 0 & 598 & 27.14 & 27.14 & -85.7 \\
\hline 23 & & 0.00 & 0 & 0 & 598 & 27.0109 & 27.02 & -76.3 \\
\hline 24 & & 0.00 & 0 & 0 & 598 & 26.8843 & 26.89 & -67.0 \\
\hline & & & & Total: & 13973 & & Total: & -1412 \\
\hline
\end{tabular}




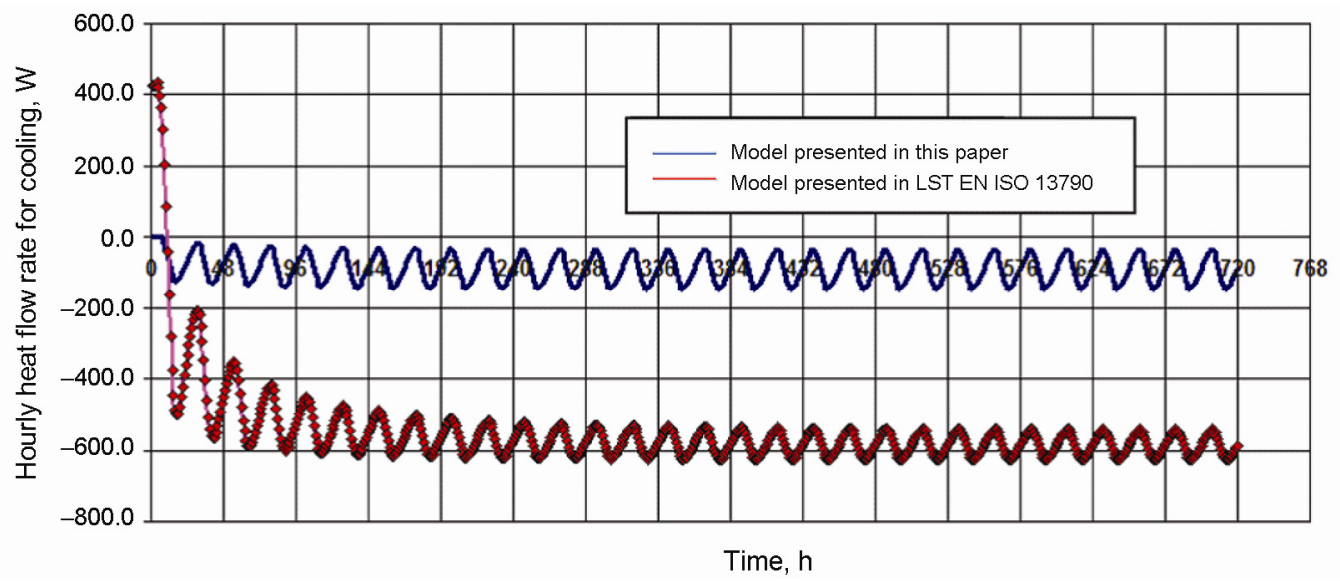

Fig. 7. Hourly heat flow rate required for cooling in July, calculation results applying two different hourly calculation methods

Table 4. Energy demand for cooling, calculation results by three different calculation methods at various outdoor temperatures

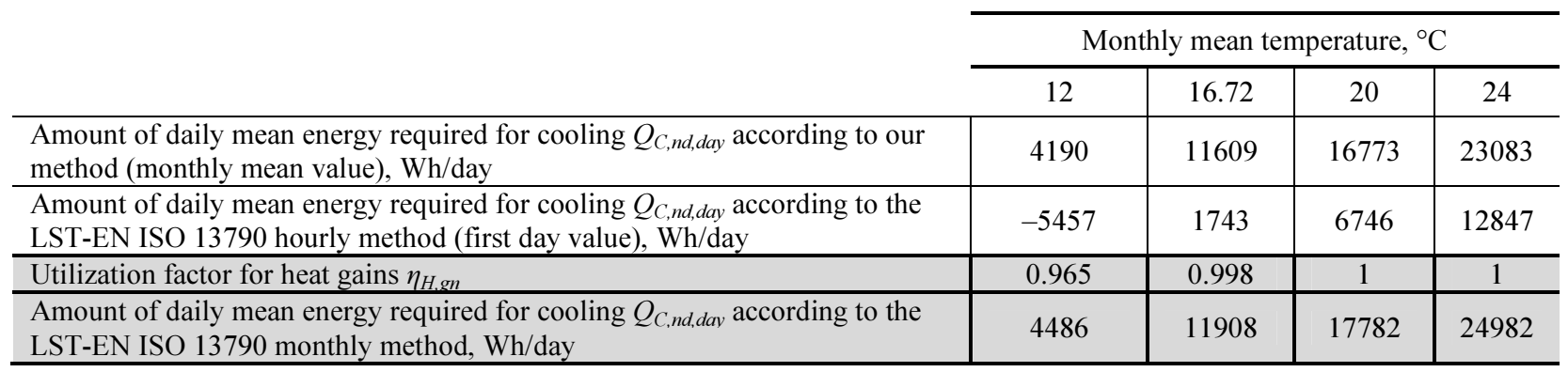

The calculation result of cooling energy demand $(11912 \mathrm{Wh} /$ day) differs from the monthly mean result of our hourly calculation method $(2109 \mathrm{Wh} /$ day $)$ by more than 5 times. Additionally, this result $(11912 \mathrm{Wh} /$ day $)$ is almost 7 times higher than the first day calculation result (1743 Wh/day) obtained by the LST EN 13790 (2008) hourly method. Similarly as in case of heating energy demand calculations, the differences between our and LST EN 13790 (2008) monthly methods emerge due to the different assessment of solar heat gains admitted indoors.

The monthly method in LST EN 13790 (2008) assumes that the whole amount of solar radiation admitted indoors turns into long wave thermal energy. In other words, it is assumed that solar radiation absorption coefficient of inside surfaces of the rooms is $\alpha_{s w}=1$.

The hourly calculation method (LST EN 13790 2008) takes into account the fact that with the enlargement of solar heat gains, the indoor temperature rises; likewise, the heat losses of the rooms increase in the calculation of energy demand for cooling. It means that not all solar heat gains are related to cooling energy demand, i.e., it is assumed that a $\left(1-\eta_{C, l s}\right)$ part of transmission and ventilation heat losses are not related to the energy required for cooling of the rooms.

Our hourly calculation method determines energy indices for cooling of the building according to Eqs. (26) and (27) for each hour of the day and the hourly indoor and outdoor temperatures are taken into account as well. Therefore, there is no need to introduce any correctives to the calculation results.
For more particular analysis of both methods mentioned above additional calculations using different monthly mean outdoor temperatures were carried out. It was assumed that solar radiation absorption coefficient of indoor surfaces is the same as in the LST EN 13790 (2008) method, i.e., $\alpha_{s w}=1$ calculation according to our hourly method. In the calculations, the data of solar radiation was taken from Table 3 . The calculation results are given in Table 4 which also contains the results received applying the hourly method of LST EN 13790 (2008).

Table 4 shows that the results of our hourly method for cooling energy need are much closer to the results of the LST EN 13790 (2008) monthly method than to the results of the LST EN 13790 (2008) hourly method.

\section{Experimental check-up}

The check-up of the considered calculation methods was carried out in the rooms with one external wall at interjacent floor. The rooms were equipped with office furniture and floor covering of linoleum. The colour of all internal surfaces was assumed to be pale grey. The other partitions were facing the rooms with similar indoor climate. Thus, the heat exchange with other rooms was negligible and was not taken into account.

The main characteristics of the selected rooms: orientation N-E, (azimuth $58^{\circ}$ ), heated area $A_{f}=18.18 \mathrm{~m}^{2}$, height $2.85 \mathrm{~m}, \alpha_{s w, s i}=0.6, C_{m}=1868 \mathrm{Wh} / \mathrm{K}$; windows vertical, $A_{w d, k}=7 \mathrm{~m}^{2}, \quad U_{w d}=1.9 \mathrm{~W} /\left(\mathrm{m}^{2} \cdot \mathrm{K}\right), \varepsilon_{l w, w d s e}=0.9$, $\alpha_{s w, w d, s e}=0.12, F_{r, w d}=0.5, F_{s h, w d}=0.9, F_{F}=0.26, g_{g l, n, w d}=$ $0.55, h_{s e, c}=25 \mathrm{~W} /\left(\mathrm{m}^{2} \cdot \mathrm{K}\right)$, his $=7.7 \mathrm{~W} /\left(\mathrm{m}^{2} \cdot \mathrm{K}\right)$; the area of 
external wall $A_{w}=7.39 \mathrm{~m}^{2}, U_{w}=1.0 \mathrm{~W} /\left(\mathrm{m}^{2} \cdot \mathrm{K}\right), \varepsilon_{l w, w, s e}=$ $0.9, \alpha_{s w, w, s e}=0.12, F_{r, w}=0.5, F_{s h, w}=0.9$.

Other data: the vents in the rooms were sealed, so air infiltration was eliminated $\left(n=0 \mathrm{~h}^{-1}\right)$; indoor air temperature was maintained at $16^{\circ} \mathrm{C}\left(\theta_{i, H, d s}=16^{\circ} \mathrm{C}\right)$.

Outdoor air parameters were registered by a climate station near the building every minute. Solar radiation to the horizontal surface was measured directly and then recalculated for the considered azimuth.

Indoor air temperature was measured in four places.

Electric air heater of $19.8 \mathrm{~W}$ power was used in the rooms, and internal heat gains were assumed to be continuous and equal to $1.1 \mathrm{~W}$.

The measurements of mean indoor temperature and outdoor air parameters of four days period were taken for the analysis at the check-up of the calculation precision and are presented in Fig. 8.

The comparison of the calculation results according to our method and the hourly method presented in LST EN 13790 (2008) with experimental data is given in Fig. 9.

On the basis of the result comparison, it could be stated that the trends of temperature changes in the rooms are described more accurately when the suggested method is used than by the standard hourly method of LST EN ISO 13790 (2008). It ought to be admitted that both calculation methods, hourly from LST EN ISO 13790
(2008) and the one introduced in this paper, are used for the design purposes mostly, for this reason, the generalized thermal-technical data of the rooms (the area of internal surfaces, effective heat capacity of the building, solar radiation absorption coefficient) are applied. Because of this, the obtained results describe the principal trends of temperature change in the rooms in regard to the thermal-technical properties of the building construction, indoor air parameters, and climate impact.

The temperature in the considered rooms during the day ought to vary gradually due to the heat gains from outside according to the calculation results, while the actual temperature changes occur almost at the same time with alteration of solar radiation flux. A certain part of surfaces in real rooms have low heat capacity, they quickly become warm or cool, and heat is instantly transferred to the indoor air by convection or radiation. The surfaces with high heat capacity (massive) slowly respond to the short-tempered temperature changes in the rooms caused by the surfaces of low heat capacity. Therefore, both the properties of finish materials and equipment, and the generalized thermal-technical data of the considered rooms have a significant influence on the actual trend of temperature change. This must be taken into account in case of design and analysis of thermal behaviour and energy demand for heating or cooling of the rooms.

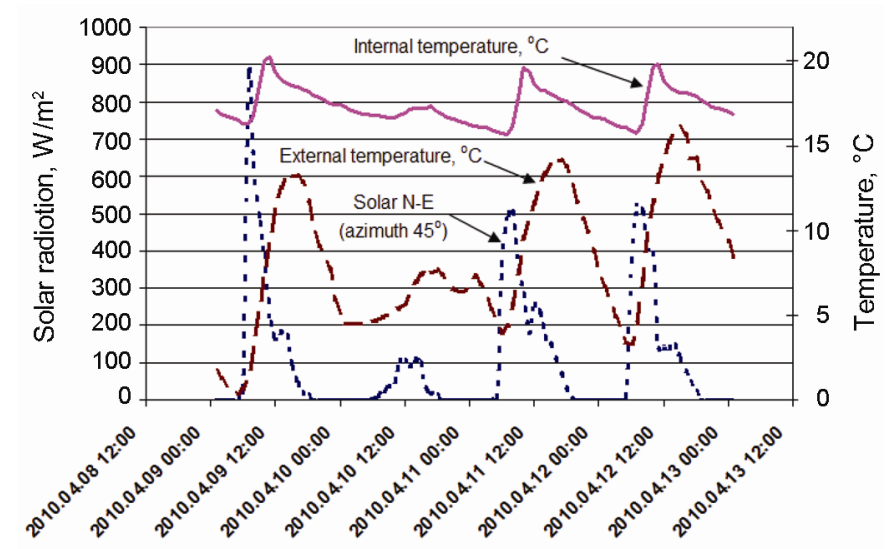

Fig. 8. Experimental data

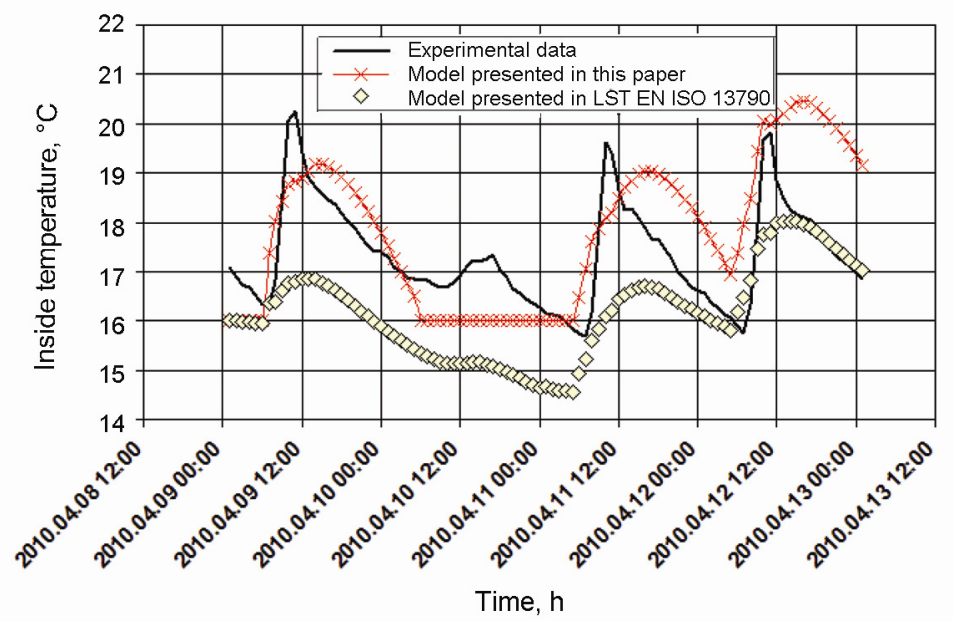

Fig. 9. Experimental data and calculation results applying two different hourly calculation methods 


\section{Conclusions}

The methods currently used for the calculations of external solar heat gains do not consider the fact that the rate of solar thermal radiation energy admitted indoors through transparent elements of the building is not adequate to the rate of thermal energy absorbed by the rooms. The rate of transition of radiated solar short wave thermal energy into the long wave thermal energy depends on the solar radiation absorption coefficient of the inside surfaces of the rooms. The value of solar radiation absorption coefficient of internal surfaces has a great impact on the amounts of absorbed external heat gains in the rooms. Therefore, according to the calculations applying the hourly method introduced in this paper and estimating the solar radiation absorption coefficient of indoor surfaces, the determined energy demand for heating of the rooms is greater, and lesser for cooling than the values obtained by the monthly calculation method of LST EN ISO 13790 (2008) usually applied in practice.

The method proposed in this paper differs from others because it estimates physical laws of transition of short wave solar radiation admitted indoors into long wave thermal energy. This method is also different from most of others because it uses hourly monthly mean data for each hour of the day rather than daily mean global solar radiation data.

The calculation of internal heat gains and sky dome radiation by our method is linked to the physics of phenomena and the related values of the mentioned gains slightly differ from the method of LST EN ISO 13790 (2008).

The proposed hourly calculation method enables calculating the indoor temperature each hour of the day and hourly energy demand for heating and cooling of the rooms.

After the analysis of different calculation methods of energy demand for buildings, it was determined that if the whole solar radiation passed indoors through glazed fenestration and were taken as external heat gains, i.e., as it is given in the LST EN ISO 13790 (2008) method, the calculation results of monthly mean energy demand for heating and cooling of the building would only slightly differ from the calculation results of the monthly method of LST EN ISO 13790 (2008).

\section{References}

ASHRAE Fundamental Handbook. 2009. American Society of Heating, Refrigerating and Air-Conditioning Engineers. $880 \mathrm{p}$.

Banionis, K.; Stankevičius, V.; Monstvilas, E. 2011. Heat exchange in surfaces of ventilated lightweight steel roof's coatings, Journal of Civil Engineering and Management 17(1): 88-97. http://dx.doi.org/10.3846/13923730.2011.556180

Carmody, J.; Seltowitz, S.; Lee, E. S.; Arasteh, D.; Willmert, T. 2004. Window systems for high-performance buildings. New York - London: W. W. Norton \& Company. 400 p.

Corrado, V.; Fabrizio, E. 2007. Assessment of building cooling energy need through a quasi-steady sate model: simplified correlation of gain-loss mismatch, Energy and Buildings 39(5): 569-579.

http://dx.doi.org/10.1016/j.enbuild.2006.09.012

Corrado, V.; Mechri, H. E.; Fabrizio, E. 2007. Building energy performance assessment through simplified models: Application of the ISO 13790 quasi-steady state method, in Proc. of the 10th Conference of the International Building Performance Simulation Association, 3-6 September, 2007, Tsinghua University, Beijing, China, 79-86.

Directive 2010/31/EU of the European Parliament and of the Council of 19 May 2010 on the energy performance of buildings, Official Journal of the European Union 53: 1335.

Ginevičius, R.; Podvezko, V.; Raslanas, S. 2008. Evaluating the alternative solutions of wall insulation by multicriteria methods, Journal of Civil Engineering and Management 14(4): 217-226. http://dx.doi.org/10.3846/1392-3730.2008.14.20

Josikalo, J.; Kurnitski, J. 2007. Performance of EN ISO 13790 utilisation factor heat demand calculation method in a cold climate, Energy and Buildings 39(2): 236-247. http://dx.doi.org/10.1016/j.enbuild.2006.06.007

Jurelionis, A.; Isevičius, E. 2008. CFD predictions of indoor air movement induced by cold window surfaces, Journal of Civil Engineering and Management 14(1): 29-38. http://dx.doi.org/10.3846/1392-3730.2008.14.29-38

Kalema, T.; Jóhannesson, G.; Pylsy, P.; Hagengran, P. 2008. Accuracy of energy analysis of buildings: A comparison of a monthly energy balance method and simulation methods in calculating the energy consumption and the effect of thermal mass, Journal of Building Physics 32(2): 101-130. http://dx.doi.org/10.1177/1744259108093920

LST EN ISO 13790 Energy performance of buildings, Calculation of energy use for space heating and cooling. Brussels: European committee for standardization, 2008. $165 \mathrm{p}$.

LST EN ISO 6946 Building components and building elements, Thermal resistance and thermal transmittance, Calculation method. Brussels: European committee for standardization, 2008. $31 \mathrm{p}$.

Motuziene, V.; Juodis, E. S. 2010. Simulation based complex energy assessment of office building fenestration, Journal of Civil Engineering and Management 16(3): 345-351. http://dx.doi.org/10.3846/jcem.2010.39

Nielsen, T. R.; Svendsen, S. 2005. Simplified hourly calculation of energy performance in accordance with the Energy Performance of Buildings Directive [cited 10 October 2011]. Available from internet: http://web,byv,kth,se/bphys/reykjavik/pdf/art_124.pdf

Orosa, J. A. C.; Oliveira, A. 2010. Implementation of a method in EN ISO 13790 for calculating the utilisation factor taking into account different permeability levels of internal coverings, Energy and Buildings 42(5): 598-604. http://dx.doi.org/10.1016/j.enbuild.2009.10.030

Šeduikyte, L.; Paukštys, V. 2008. Evaluation of indoor environment conditions in offices located in buildings with large glazed areas, Journal of Civil Engineering and Management 14(1): 39-44. http://dx.doi.org/10.3846/1392-3730.2008.14.39-44

Sjösten, J.; Olofsson, T.; Golriz, M. 2003. Heating energy use simulation for residential buildings, in Proc. of the 8th International IBPSA Conference, 11-14 August, 2003, Eindhoven, Netherlands, 1221-1226. 
Urbikain, M. K.; Sala, J. M. 2009. Analysis of different models to estimate energy savings related to windows in residential buildings, Energy and Buildings 41(6): 687-695. http://dx.doi.org/10.1016/j.enbuild.2009.01.007

Van Dijk, H.; Spiekman, M.; de Wilde, P. 2005. A monthly method for calculating energy performance in the context of European building regulations, in Proc. of the 9th International IBPSA Conference, 15-18 August, 2005, Montréal, Canada, 255-262.
Yohanis, Y. G.; Norton, B. 1999. Utilization factor for building solar-heat gain for use in a simplified energy model, Applied Energy 63(4): 227-239. http://dx.doi.org/10.1016/S0306-2619(99)00032-X

Zinzi, M.; Agnoli, S.; Fasano, G.; Romeo, C. 2008. Energy performance calculation methods for the Italian existing dwellings: a comparison, in Proc. of the 25th Conference on Passive and Low Energy Architecture (PLEA 2008), 22-24 October, Dublin, Ireland. 6 p.

Edmundas MONSTVILAS. Doctor, Senior Researcher at the Laboratory of Thermal Building Physics of the institute of Architecture and Construction, KTU. Research interests: heat transfer and thermal insulation, technical properties of thermal insulation products.

Vytautas STANKEVIČIUS. Doctor Habil. Full Professor, Chief Researcher at the Laboratory of Thermal Building Physics of the institute of Architecture and Construction, KTU. Research interests: heat transfer, technical properties of thermal insulation products.

Jūratė KARBAUSKAITE். PhD. Senior Researcher at the Laboratory of Thermal Building Physics of the institute of Architecture and Construction, KTU. Research interests: heat transfer and thermal insulation, technical properties of thermal insulation products.

Arūnas BURLINGIS. PhD. Senior Researcher at the Laboratory of Thermal Building Physics of the institute of Architecture and Construction, KTU. Research interests: heat transfer and thermal insulation, technical properties of thermal insulation products.

Karolis BANIONIS. PhD. Researcher at the Laboratory of Thermal Building Physics of the institute of Architecture and Construction, KTU. Research interests: heat transfer, thermal impacts of solar radiation. 